\title{
Building blocks for social accountability: a conceptual framework to guide medical schools
}

\author{
Robyn Preston ${ }^{1,3^{*}}$ (D), Sarah Larkins ${ }^{1,3,4}$, Judy Taylor ${ }^{1,3,4}$ and Jenni Judd ${ }^{1,2,3,4}$
}

\begin{abstract}
Background: This paper presents a conceptual framework developed from empirical evidence, to guide medical schools aspiring towards greater social accountability.

Methods: Using a multiple case study approach, seventy-five staff, students, health sector representatives and community members, associated with four medical schools, participated in semi-structured interviews. Two schools were in Australia and two were in the Philippines. These schools were selected because they were aspiring to be socially accountable. Data was collected through on-site visits, field notes and a documentary review. Abductive analysis involved both deductive and inductive iterative theming of the data both within and across cases.

Results: The conceptual framework for socially accountable medical education was built from analyzing the internal and external factors influencing the selected medical schools. These factors became the building blocks that might be necessary to assist movement to social accountability. The strongest factor was the demands of the local workforce situation leading to innovative educational programs established with or without government support. The values and professional experiences of leaders, staff and health sector representatives, influenced whether the organizational culture of a school was conducive to social accountability. The wider institutional environment and policies of their universities affected this culture and the resourcing of programs. Membership of a coalition of socially accountable medical schools created a community of learning and legitimized local practice. Communities may not have recognized their own importance but they were fundamental for socially accountable practices. The bedrock of social accountability, that is, the foundation for all building blocks, is shared values and aspirations congruent with social accountability. These values and aspirations are both a philosophical understanding for innovation and a practical application at the health systems and education levels.
\end{abstract}

Conclusions: While many of these building blocks are similar to those conceptualized in social accountability theory, this conceptual framework is informed by what happens in practice - empirical evidence rather than prescriptions. Consequently it is valuable in that it puts some theoretical thinking around everyday practice in specific contexts; addressing a gap in the medical education literature. The building blocks framework includes guidelines for social accountable practice that can be applied at policy, school and individual levels.

Keywords: Social accountability, Medical schools, Medical education, Conceptual framework, Australia, The Philippines

Abbreviations: ADZU SOM, Ateneo de Zamboanga University School of Medicine; FUSOM, Flinders University (Continued on next page)

\footnotetext{
* Correspondence: robyn.preston@jcu.edu.au

${ }^{1}$ College of Medicine and Dentistry, Division of Tropical Health and Medicine,

James Cook University, 1 James Cook Drive, Townsville, QLD 4811, Australia

${ }^{3}$ Anton Breinl Research Centre for Health Systems Strengthening, James

Cook University, Townsville, Australia

Full list of author information is available at the end of the article
} 


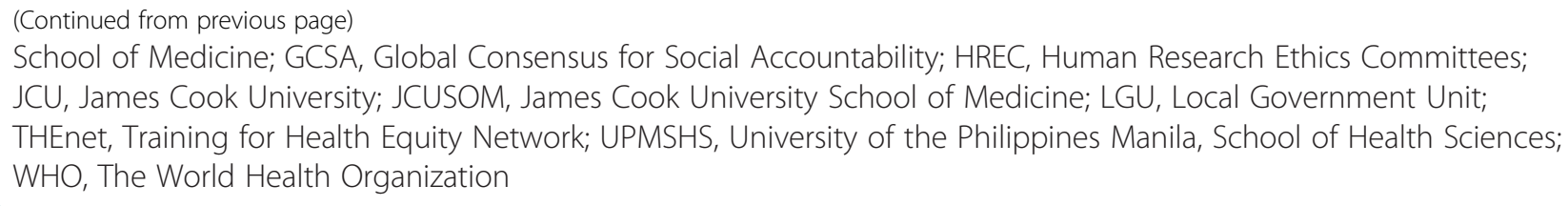

\section{Background}

Medical schools aspiring towards social accountability deem themselves responsible for meeting the health needs of the communities that they serve ${ }^{1}[1]$. They orientate their education, research and service to the health needs of the population [2]. From the 1980s to 2000s Dr Charles Boelen and other colleagues at the World Health Organization (WHO) fostered the theory of socially accountable medical education and socially accountable medical schools [3]. These authors then developed the conceptualization, production and utilization grid, the values of social accountability (relevance, equity, costeffectiveness and quality) and the Towards Unity for Health partnership pentagram [1-10]. From the 2000s to 2010s there was re-interest in measuring and evaluating socially accountable medical schools; including a number of initiatives at individual schools and collectively. These encompassed the Lancet's Independent Commission on Health Professional Education for the 21st Century [11] and the call for socially accountable medical education to be aligned with accreditation systems.

Despite the advancement of conceptual frameworks, many medical schools aspiring to social accountability had developed independently from the theoretical concepts of socially accountable medical education. There are gaps in the literature around the key factors, both externally and internally, influencing medical schools advancing towards social accountability and the way in which they operate. While the theory of social accountability identifies key principles, how these play out in different schools is the topic of this paper. We present a conceptual framework, derived from empirical research from practice, describing the building blocks for socially accountable medical education.

\section{Methods}

A social justice perspective, drawing upon constructivism and critical theory, was utilized throughout this research. This perspective is linked with the phenomena of social accountability and the epistemological position of the researchers $[12,13]$. The voices of all participants had to be heard and given equal weight in contributing to new knowledge. This was important as this research included cases from more financially and less financially resourced countries. Recent literature in medical education has criticized global medical school partnerships as post-colonialist or neo-imperialist enterprises, with imbalances in power relationships and benefits $[14,15]$. Furthermore, the powerful profession of 'the medical doctor' was investigated. Issues of power and professionalism are played out between and within health professionals [16]. One way in which socially accountable medical education has been defined and implemented is in the context of medical dominance and the changing role of 'the doctor' as a professional and 'leader' in the health world [16-21]. The authors attempted to actively acknowledge and confront that research can reproduce or enforce existing power structures. Researchers aimed to be self-reflective and self-critical of the values and interest that underlie social theory [22] and explicitly declare their own assumptions [23].

This project utilized multiple case studies [13, 24-26] of four medical schools in Australia and in the Philippines. ${ }^{2}$ Cases were sampled on the basis of maximizing the likelihood of demonstrating a range of contextual influences [13] and membership of the Training for Health Equity Network (THEnet), a collaboration formed in 2008 of 11 health professional schools aspiring towards social accountability ${ }^{3}$ [27-32]. Seventy-five purposively sampled faculty, students, health professionals and community members were interviewed (Table 1) on their understanding of social accountability and what contextual factors had influenced their schools. From a review of the literature these were hypothesized to be:

- Profile of the local health workforce;

- Partnerships with the local, state and national health system; and

- Partnerships between the medical school and its 'community'.

(Additional file 1 outlines examples of the interview guides). Site visits were undertaken by the principal researcher (RP) to all four schools, including a rural area at each location. Documents analysed included peer reviewed papers, meeting reports, websites and policies [33].

Data analysis was abductive and involved deductive and inductive iterative thematic analysis of qualitative data [34], both within case and across cases [25, 35]. All interviews were transcribed verbatim and any changes identified by participants during verification were incorporated into the transcripts. Field notes, and notes from documentary analysis were transcribed and NVivo 10 
Table 1 Individual Participants [3]

\begin{tabular}{|c|c|c|c|c|c|c|}
\hline \multirow[t]{2}{*}{ Type } & \multirow[t]{2}{*}{ Description } & \multicolumn{5}{|l|}{ Participants } \\
\hline & & $\begin{array}{l}\text { Case } 1 \\
\text { FUSOM }\end{array}$ & $\begin{array}{l}\text { Case } 2 \\
\text { JCUSMD }\end{array}$ & $\begin{array}{l}\text { Case } 3 \\
\text { ADZUSOM }\end{array}$ & $\begin{array}{l}\text { Case } 4 \\
\text { UPMSHS }\end{array}$ & Total \\
\hline Staff/Faculty & $\begin{array}{l}\text { "Champions at schools." Any staff members } \\
\text { who know about social accountability and/ } \\
\text { or the history of the school, including leaders } \\
\text { and former leaders. }\end{array}$ & 11 & 11 & $\begin{array}{l}7 \text { (including } 2 \\
\text { former students) }\end{array}$ & $\begin{array}{l}9 \text { (including } 2 \\
\text { former students) }\end{array}$ & 38 \\
\hline Students & $\begin{array}{l}\text { Student at any year level who are interested in } \\
\text { social accountability. In Australia, students who } \\
\text { were involved in the rural and/or international } \\
\text { health student groups. }\end{array}$ & 4 & 4 & 5 & 4 & 17 \\
\hline Health Sector & $\begin{array}{l}\text { A person holding a position involved in policy, } \\
\text { medical education at a state, regional or } \\
\text { provincial level, who has had involvement in } \\
\text { the school. A preceptor or someone from a } \\
\text { hospital or the health department, who has } \\
\text { been involved with the school. At two schools } \\
\text { (UPMSHS and ADZU) this included Graduates } \\
\text { of the school who may also have a teaching } \\
\text { or preceptor role. }\end{array}$ & $\begin{array}{l}2 \text { (including } \\
1 \text { preceptor) }\end{array}$ & $\begin{array}{l}2 \text { (including } 1 \text { joint } \\
\text { JCUSOM appointment } \\
\text { with Department of } \\
\text { Health) }\end{array}$ & $\begin{array}{l}6 \text { (all had } \\
\text { teaching roles } \\
\text { and all were } \\
\text { former students) }\end{array}$ & $\begin{array}{l}4 \text { (including } 3 \\
\text { former students; all } \\
\text { involved in teaching } \\
\text { students) }\end{array}$ & 14 \\
\hline Community & $\begin{array}{l}\text { "Champions at schools." Any community } \\
\text { person involved in the school in teaching } \\
\text { or research or at rural placement sites. }\end{array}$ & 1 & 1 & 2 & 2 & 6 \\
\hline Total & & 18 & 18 & 20 & 19 & 75 \\
\hline
\end{tabular}

was used to store, organize and analyze data [36]. Within case analysis was undertaken by abductive coding; the combination of a predefined deductive coding framework (set by the questions and the three contextual issues obtained from the literature review) and open coding that recorded emerging ideas $[3,37]$. Themes were developed and finalized through the constant comparison method, drawing out amalgamated ideas from the codes. Initial similar themes across cases were developed from data immersion. Themes were refined and connections between themes mapped using site-order descriptive matrixes for each of these questions [38]. Coder triangulation was undertaken and negative instances that challenged initial assumptions and interesting outliers were identified to ensure that conclusions were drawn from the data [39]. Themes that emerged consistently across all data were categorized as core themes. Concepts were then further developed in relation to the research questions and from the literature. There were consistent themes across all cases, regardless of the country or other factors. This paper reports on the cross-case analysis.

\section{Results}

Local and national workforce issues and health needs were important external contextual factors that influenced all four socially accountable medical schools:

So workforce was the reason the government funded it [the medical school] so absolutely if you move back from government funding [it] was workforce, workforce, workforce... (FU1_staff).
Workforce needs were defined as shortages of doctors in underserved areas and the mal-distribution between urban and rural areas. All institutions had geographic proximity to a defined region of workforce need, or sent their students there for a lengthy period, often coexisting with populations with the poorest health indicators or greatest health needs. Programs and schools were established to meet these workforce and health care needs and there were some innovations in both the Philippines and in Australia. The workforce and health system needs influenced how students were trained and the desired outcomes of their training. Schools produced graduates who would be well-equipped to meet the workforce and health system needs. Placements ensured that graduates were personally and professionally equipped to work in areas of workforce need.

An important contextual influence came from the communities the medical schools served. These differed:

- At the population level: Associated with the influence of workforce, at some schools the population of communities and their different health needs had influenced the establishment and orientation of the schools;

- As communities of place and interest with a formal or informal community engagement policy: Some schools had formal community engagement policies and informal ways to work with communities of place and interest; sometimes informed by the wider university policy; and, 
- As students becoming part of the communities: Students undertake placements in underserved communities and are integrated into community life:

\begin{abstract}
"That's why you are sent to communities that do not have water, that do not have electricity, to see that not everyone is the same. So that opens our eyes. This is the social situation of our country, not everyone is privileged, not everyone can go to school, and not everyone has the chance to eat three square meals a day. This is our situation in our region and you're here, you're privileged to study medicine, it's for you to help these people" (ADZU2_student).
\end{abstract}

Government policy was an influence in the Australian case studies because workforce need was a political driver. A number of Australian government policies and programs were designed to address rural workforce issues such as rural placements [40-43]:

\section{In fact you could say that the Commonwealth [government] now has [become], to some extent, our main champion because without them we would not [have] the money and the policy wouldn't have developed the way it has and so on (FU8_Health).}

In the Philippines, due to the prevailing culture of export driven medical and health professional education, government policy and programs were not highlighted as influencing socially accountable medical schools.

Local politics and local politicians were a powerful contextual issue that influenced social accountability at all four medical schools. While the local government sector had more influence in the Philippines, in both countries participants saw the local or first level of government as being part of the community. In the Philippines the health system is devolved with local officials and local politics influencing the budget and this could either impede or enhance student selection, placements, and graduate job placements:

We need to have a strong partnership or bond with the Local Government Unit (LGU) because it is the LGU that identifies which health workforce they need, so we train the students to become the health workers that they need. (UPMSHS16_staff).

In Australia, while the local government did not have as much influence over the health system, support was provided through other initiatives that have involved local councils and medical education such as the provision of housing and social support on placements and in some cases, local councils owning primary health care services.
The values and missions of affiliated universities, when they were aligned with social accountability, were an important contextual influence. Many of the staff's own beliefs, including social justice and a religious association, were consistent with overall values. In addition, some schools were part of universities that had a wider institutional culture that encouraged going against the norm to develop innovative programs. For example, difference and freedom from tradition gave FUSOM an opportunity to focus on "innovation" or being able to have "... a different approach to the way they did business [so there] was a fair degree of risk taking on their behalf, innovation, opportunity, that perhaps came with being a new kid on the block" (FU8_health).

Financial, human and infrastructural resources were also a contextual influence in two ways. In some contexts lack of resources has spurred innovation [30, 32]. While both the Filipino schools had received international support at establishment and had continued partnerships with schools in more resourced countries; a lack of resources also promoted self-reliance and a culture of independence and empowerment. There was also an awareness that locals were better equipped to develop the schools; and a creative ability to "... make do with what we have" (UPMSHS5_staff). In Australia, government funding was essential for socially accountable programs, such as rural placements, to be established and sustained. Indeed these programs were accurately deemed more expensive than conventional medical education programs due to decentralization to rural areas.

Leaders and individual "champions" of social accountability influenced the organizational culture of the schools and the type of people attracted to working in the schools and drove innovation. Staff and students were drawn to working with leaders and at institutions that had these values. These leaders' values, medical experience in the region and personal and professional connections established, re-orientated or sustained the school. Champions from across the health, education and political sectors lobbied for the establishment of new schools or programs:

...they're not just people who look at the problem in front of their nose, they take a step back and think. That sort of controlled rage really, is a drive to change things. Because it takes a lot of effort to change the way things are done, so when I say controlled rage I suppose you know the fire in the belly (JCU12_staff).

All schools were inaugural members of the Training for Health Equity Network (THEnet) and therefore had articulated a common understanding of social accountability [28-32]. In general, THEnet legitimized what schools were doing; membership and interaction with this group clarified 
existing practices and connected the schools with a global movement. All schools had an understanding of resisting traditional models of medical education. Belonging to this group also helped members interpret the high level WHO policies or directives into practical guidelines confirming existing practice. Through THEnet leaders and staff were able to represent their schools on the $\mathrm{WHO}$ and other global forums and groups interested in social accountability. Leaders also developed alliances in medical education that assisted with their own professional development.

All schools had an understanding of resisting traditional models of medical education. An underlying assumption that was not fully explored by the participants was the idea of being different and defending this difference. This was articulated at JCUSOM as the health and community needs of the geographical north being different. At FUSOM participants discussed the difference and innovation of the university and school. Respondents knew that ADZU SOM had always been against the mainstream medical education. At UPMSHS participants noted they were doing what they could with little resources. The schools naturally challenge orthodoxies, and are seen as alternative models for health professional education [40] but have also faced "institutional isolation and skepticism from more traditional medical schools" [28] (p.340). There was a shared understanding that while the schools may be critiqued for persisting against opposition, subverting dominant paradigms or doing that which was thought impossible by more traditional schools, there was also a defiant confidence that resistance to current models of medical education is 'the right thing to do' $[27,44]$.

\section{Discussion \\ Conceptual framework: building blocks for socially accountable medical schools}

The building blocks conceptual framework (Fig. 1) was created by analyzing the internal and external factors influencing the selected medical schools and demonstrates what 'building blocks' or conditions might be necessary to assist medical schools moving towards social accountability. These building blocks are classified as environmental (macro), school (meso) or people (micro) factors. The 'bedrock' of social accountability applies at all levels: shared values congruent with social accountability. While many of these building blocks are similar to those conceptualized in social accountability theory, this conceptual framework is informed by what happens in practice - empirical evidence rather than prescriptions. Consequently it is valuable in that it puts some conceptual thinking around everyday practice. These prescriptions are based on data from the four cases and cannot hope to cover all the nuances of practice in widely varying contexts.

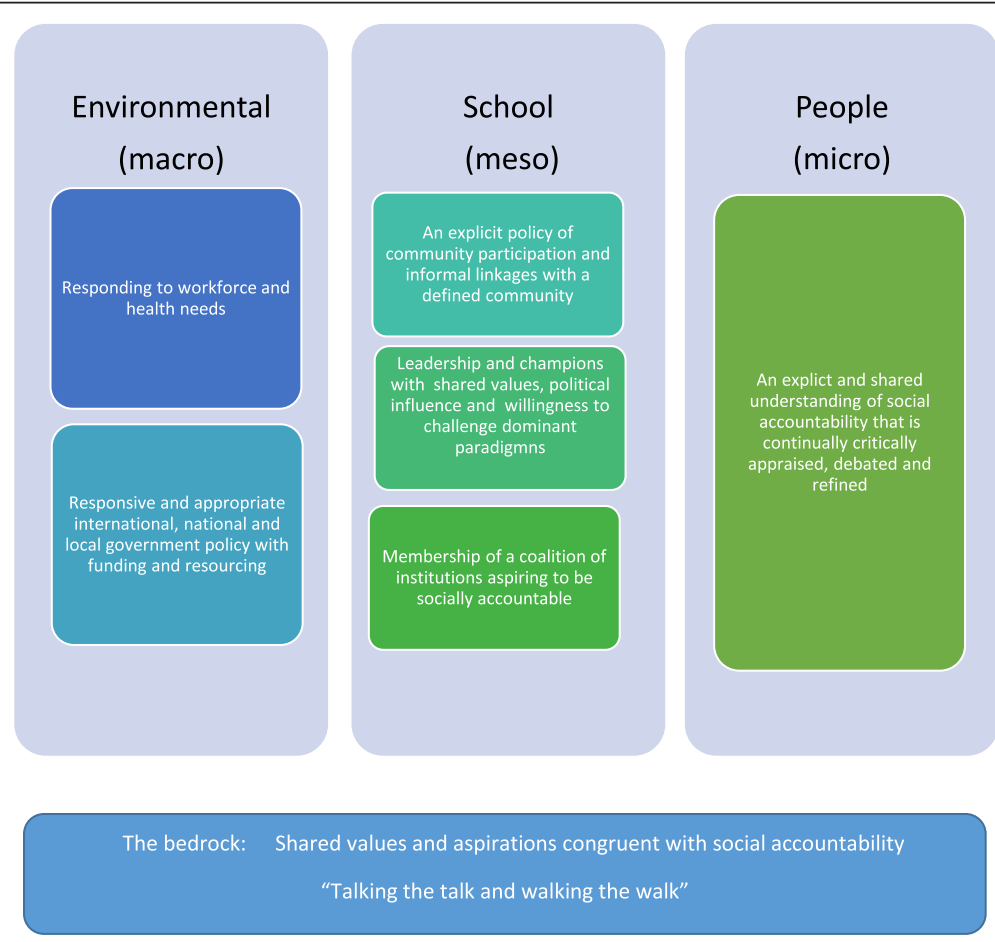

Fig. 1 Building Blocks for Socially Accountable Medical Schools 


\section{Environmental factors}

Environmental factors or macro factors are those outside the medical school. They include the local, regional or national workforce and health needs as well international, national and local government policies and resourcing.

\section{Responding to workforce and health needs}

Workforce was a major influence of schools aspiring to be socially accountable as the main focus of socially accountable medical schools should be meeting workforce needs and understanding the health issues of their region. This finding concurs with the literature on socially accountable medical schools $[1,29,45]$. Schools in areas of workforce need have a more holistic or "whole of school" approach to social accountability as the health system needs are very apparent and hard to ignore.

\section{What this means in practice}

To understand workforce issues the curriculum of the school should include an analysis of the local workforce situation as well as key health issues. Leaders and staff need to have professional experiences and connections in areas of health and workforce need.

\section{Responsive and appropriate international, national and local government policy with funding and resourcing}

The second building block for socially accountable medical education is the partnership that schools form with government, the health sector, and health care policy makers in health professional education. Governments play different roles depending on the country but the governmental and political context is always important. In Canada, socially accountable medical schools have been mandated in Health Canada policy since 2001 [45, 46]. In more financially resourced countries, such as Canada or Australia, socially accountable programs could not persist without government funding.

In contrast, government policies that have restricted social accountability in the Philippines were overcome due to other factors such as strong leadership and people within innovative schools. The differences in political organization, or between a more centralized and decentralized government, might explain some of the differences in Australia and the Philippines. The decentralized Filipino health system may mean that local initiatives are more influential than government policy.

\section{What this means in practice}

Medical schools and their leaders need to lobby for medical education and health policies that support the principles of social accountability. For example, for government policies and funding programs that support medical schools in regional and rural settings and in areas where there is workforce need. Medical schools can also adapt and promote government workforce policy or aspects that are socially accountable (for example rural placements). The need for these policies should be promoted and explained in terms of graduate outcomes and long-term impact on health needs of communities. Medical schools should also advocate for a balance of adequate resources with room for innovation and adaptation to the local contexts. Accreditation can motivate medical schools towards social accountability. Medical schools should call for national accreditation systems to include assessment of social accountability. Indeed progress has started on moving the World Federation for Medical Education accreditation standards in this direction [47].

\section{School factors}

School or meso factors include those factors within medical schools including leaders, people (staff/faculty/ students) and policies.

\section{An explicit policy of community participation and informal linkages with a defined community}

Community placements, and connections between underserved or rural communities and their health needs, enable students to experience the realities of professional and community life [44, 48-50]. The types of connections between schools and communities vary again depending on the context. The idea of service and links with the community were stronger in the Philippines where there was a sense of personal responsibility. Participants in the Philippines saw the students on placement as 'helping' with health and community services. In Australia however the imperative for workforce is more political or organizational and government resources are assigned to this endeavor through programs such as the Rural Clinical Teaching Program [51].

While all schools were influenced by communities, the community may not have appreciated or fully understood the importance of this influence. In addition, the connections may be limited and there might be a lack of authentic engagement and/or partnership. In a critical review Hunt et al. noted that university-community engagement was mainly frequently understood as outreach or service and no articles discussed mutually beneficial or collaborative partnerships with communities [52].

Student placements are one of the major ways through which links are made between rural or underserved populations and the medical school [53]. Community placements were also responsible for changing or confirming student attitudes and aspirations. Long term communitybased medical education that develop significant relationships enhances student learning [54]. 


\section{What this means in practice}

In order to work effectively with their community a school needs to have a well-defined understanding of the communities, or the defined population that they serve, and an explicit policy about the types of community participation that are appropriate. There will be a need for engaging, partnering or connecting with the community to be undertaken in diverse ways, for example for community to be involved in strategic planning. The community participation strategy of the school needs to be well resourced, achievable and assessed or evaluated.

Generally, schools should partner with non-government or community-based or civil society organizations that already work in communities of need to provide teaching, research, service or health projects. To enable successful partnerships, communities need to be made more aware of their power and influence and community organizations can help facilitate this process.

\section{Leadership and champions with shared values and political influence and willingness to challenge dominant paradigms}

Strong leadership and champions can transform medical education $[30,32,55]$ and this is a building block of social accountability. In a study of Deans as "spiritual leaders", Evans [56] states that leaders should "personify and embody" the values of medicine as a profession and a vocation and "they must remind us of those values and inspire us to embrace them and be guided by them" (p. 655). In promoting social accountability leaders must have not only lived experience as a health professional but "have an iron will to succeed [as] personal experience and integrity are important in the difficult debates that will ensue" [28] (p.10). Institutional or policy barriers to change, including curriculum reform, at medical schools are likely [57-60]. Strong leaders will continue to challenge the dominant paradigms of medical education when they are not supportive of social accountability [61].

\section{What this means in practice}

In practice, leadership means three things: inspiring socially accountable values; institutionalizing them; and creating a shared understanding of social accountability at the individual, organizational, and community level. The values, medical experience in the region and personal and professional connections of leaders help establish, reorientate or sustain schools. Part of the role of the leader is to institutionalize values and support and to model the culture of social accountability. This is a sustainability step enabling these Schools to embed these values within their culture so that they are not lost when a leader moves on. There needs to be explicit acknowledgment of the type of leadership schools aspiring to be social accountable desire to institutionalize the qualities of leaders. Mentoring aspiring leaders can also ensure socially accountable leadership.

\section{Membership of a coalition of institutions aspiring to be socially accountable}

The role of a network or coalition as a building block to support social accountability is important. The Training for Health Equity Network is a community of practice $[40,62,63]$ :

"Communities of practice are groups of people who share a concern, a set of problems, or a passion about a topic, and who deepen their knowledge and expertise in this area by interacting on an ongoing basis" [63] (p. 4).

This community of practice collaborates to solve problems, shares knowledge, creates tools, and has a body of common knowledge, personal relationships, and sense of identity [63]. The influence of THEnet, and other groups of medical schools is that it "can drive change from within" [40] (p. 4) The schools were brought together due to their common goals and challenges and work collaboratively.

\section{What this means in practice}

Medical schools should join or create a coalition of institutions aspiring to be socially accountable. Coalitions can help foster the professional development of leaders into international medical education leadership roles. Connection with a coalition helps legitimize and develop social accountability, particularly when schools have alternative models of medical education. Other staff and students can be part of a community of practice and receive peer support from colleagues at other schools. A community of practice can help translate or interpret global policies and directives to the local level. These groups can provide opportunities for individual schools to highlight their work. These coalitions should continue to engage schools in the wider social accountability movements such as the WHO and Global Consensus on Social Accountability (GCSA).

\section{People factors}

People or micro factors are the values of people who make up medical schools and their wider institution including staff, students, leaders, health professionals and students. This building block is fully explored in Preston et al. [3].

\section{An explicit understanding of social accountability}

As explored by Preston et al. [3] the difference in perceptions of social accountability indicates that the term may not be universally understood and appreciated [64-70]. Furthermore, the term has danger of losing meaning if schools do not continue to critically appraise and debate the term and what it means in their own unique context. 


\section{What this means in practice}

All stakeholders need to be involved in debating and developing and operationalizing a shared understanding of social accountability to ensure it is socio-culturally appropriate to the context of the school [3]. The school community may argue that the term "social accountability" does not fully capture their mission and practice; particularly in non-English speaking settings. A local term or phase may be developed that captures the nuances and essence of the school culture. Staff students, health sector and community members could be asked "if our school was socially accountable what would it look like?" [3] In addition, as discussed by Ritz et al. schools should adopt a "critically reflexive social accountability" [69], (p. 155) that questions underlying assumptions and discourses. Dissenting views and debate should be encouraged as part of this process [3].

The personal values and beliefs of staff, leaders and student influence the organizational culture of the school. People and their values can help drive organizational change. Schools need to foster a values based approach to social accountability. This may involve personalizing social accountability so it means something to all staff, students and others involved in the school, including the health and community sectors. Strategies to influence the organizational culture of the school involve including an understanding of "social accountability" as part of the staff recruitment process (for example in selection criteria or interview questions). Applicants could be asked to describe their understanding of social accountability and how they feel they could contribute to the aspirations of the school. Furthermore, new staff could be inducted into the values of the medical school, by undertaking an orientation on socially accountable practice.

Faculty/staff need to be given opportunities to reflect and act on their own practices; to "walk the talk". Faculty development could incorporate practical projects on how to engage with underserved communities. Staff in a biomedical or laboratory research role may feel alienated from social accountability. These staff could be given opportunities to learn how social accountability applies to their work. For example, they could develop professional activities that link them with the social accountability agenda of the school. These could include projects with high schools, communities, and research focused on the priority health needs of the communities. However, schools need to appreciate and accept that not all staff will or can have socially accountable practice at the forefront of their work.

\section{The bedrock: Shared values and aspirations congruent with social accountability}

The bedrock of social accountability, that is, the foundation for all building blocks, is shared values and aspirations congruent with social accountability. These values and aspirations are both a philosophical understanding for innovation and a practical application at the health systems and education levels. The values are held by people: the community; leaders; students; faculty and health professionals. These actors or stakeholders aspire to apply these values, often in defiance of 'mainstream' health and education systems, by "walking the talk" of social accountability in their everyday work and life.

\section{Conclusions}

The nature of development of social accountability is contextually dependent, politically, historically, socially, spiritually, and economically influenced. Some schools did not term their practice as such until legitimized in this movement for socially accountable medical education. Consequently, development of practice and theory should be seen as iterative rather than prescriptive. Through the process of critical analysis to identify the most important key influences of socially accountable medical education, the building blocks become clear. These are: environmental, including workforce; funding and partnerships; internal to the school, including leadership and community engagement, and about the values of people. There are also examples given in this paper of the actions that medical schools might take to move towards social accountability. The actions are very different depending on the context but if actions are thoughtfully applied and consistent with the building blocks then this might support further movement towards socially accountable medical education.

\section{Endnotes}

"Aspiring towards social accountability" is used for schools with an explicit social accountability mandate as social accountability is recognized to be an aspirational ideal.

${ }^{2}$ Flinders University, Australia; James Cook University, Australia; Ateneo de Zamboanga University, The Philippines; University of the Philippines, Manila, School of Health Sciences, The Philippines.

3"A shared understanding of social accountability, in the context of health professional education, was a key inclusion criterion for the cases. If schools and their staff/faculty did not have a shared understanding of social accountability the design flaw would have been "but what is social accountability?" The term could have meant anything and been interpreted in divergent ways. By being members of THEnet schools, the institution had declared that they were aspiring to be socially accountable. Data collection was not distracted by philosophical discussions on what was social accountability and was the school aspiring to be socially accountable" [3] [p.3]. 


\section{Additional file}

Additional file 1: Examples of Interview guides. Examples of interview guides for faculty/staff, student, health professional and community representative interviews. (DOCX $18 \mathrm{~kb}$ )

\section{Acknowledgements}

Thank you to the Training for Health Equity Network (THEnet) Colleagues who were research mentors at three sites. Thank you to participants who invited RP into their workplaces and homes and gave their time and their knowledge to this research.

\section{Funding}

Funding for this project from the Australian Postgraduate Award; College of Medicine and Dentistry, James Cook University and the Graduate Research School, James Cook University. Apart from approving the project proposal, the funding sources have not been involved in the project in any way.

\section{Availability of data and materials}

The datasets generated during the current study are not publicly available due to confidentiality. An interview guide for the faculty/staff, student, health professional and community interviews are attached to this publication (see Additional file 1).

\section{Authors' contributions}

RP conceived and designed the study, collected and analysed the data and drafted the first manuscript. J, SL and JJ made substantial contributions to conception and design of the study and the interpretation of data. All authors have been involved in revising the manuscript critically for important intellectual content. All authors have given final approval of the version to be published. All authors have agreed to be accountable for all aspects of the work in ensuring that questions related to the accuracy or integrity of any part of the work are appropriately investigated and resolved.

\section{Authors' information}

Dr Robyn Preston BA (DevS) (Hons), PGCertDisasRefugHlth, MHSc (HealthProm), PhD is a Lecturer in the Discipline of General Practice and Rural Medicine at the College of Medicine and Dentistry; a Cohort Doctoral Studies Mentor with the Australian Institute of Tropical Health and Medicine and a member of the Anton Breinl Research Centre for Health Systems Strengthening at James Cook University, Townsville, Australia. Prof Sarah Larkins, MBBS, BMedSci, MPH\&TM, PhD, FRACGP, is an academic general practitioner, Associate Dean, Research, College of Medicine and Dentistry, Co-Director Anton Breinl Research Centre for Health Systems Strengthening, Australian Institute of Tropical Health and Medicine James Cook University.

Adjunct Associate Professor Judy Taylor PhD is researching community development with the College of Medicine and Dentistry, James Cook University, Townsville Australia and is a member of the Anton Breinl Research Centre for Health Systems Strengthening and the Australian Institute of Tropical Health and Medicine.

Dr Jenni Judd, DHSc MPH MEd DipHPE is an Adjunct Associate Professor-Principal Research Fellow College of Medicine and Dentistry, Division of Tropical Health and Medicine and Anton Breinl Research Centre for Health Systems Strengthening, and the Australian Institute of Health and Tropical Medicine, James Cook University and an Adjunct Associate Professor, School of Public Health and Social Work, Queensland University of Technology.

\section{Competing interests}

The authors declare that they have no competing interests.

\section{Consent for publication}

Not applicable.

\section{Ethics approval and consent to participate}

The James Cook University (JCU) Human Research Ethics Committee (HREC) granted ethics approval (approval number H4245).

All participants were reassured that no information recorded in the interviews would in any way identify individuals. Potential participants were provided with a participant information sheet which explained the aims of the project and information about their participation in the interviews.
Participants completed a written consent form prior to participation. Interviews were held at a time and in a place convenient for participants.

\section{Author details}

${ }^{1}$ College of Medicine and Dentistry, Division of Tropical Health and Medicine, James Cook University, 1 James Cook Drive, Townsville, QLD 4811, Australia. ${ }^{2}$ Division of Tropical Health and Medicine, James Cook University, Townsville, Australia. ${ }^{3}$ Anton Breinl Research Centre for Health Systems Strengthening, James Cook University, Townsville, Australia. ${ }^{4}$ Australian Institute of Tropical Health and Medicine, James Cook University, Townsville, Australia.

Received: 2 February 2016 Accepted: 15 August 2016

Published online: 26 August 2016

\section{References}

1. Boelen C, Heck J. Defining and measuring the social accountability of medical schools. Geneva: World Health Organisation; 1995.

2. Boelen C, Woollard R. Social accountability: The extra leap to excellence for educational institutions. Med Teach. 2011;33(8):614-9.

3. Preston R, Larkins S, Taylor J, Judd J. From personal to global: Understandings of social accountability from stakeholders at four medical schools. Medical Teacher. 2016:1-8. 10.3109/0142159X.2015.1114596.

4. Boelen C. A new paradigm for medical schools a century after Flexner's report. Bull World Health Organ. 2002;80(7):592-3.

5. Boelen C. Building a socially accountable health professions school: Toward unity for health. Education for Health. 2004;17(2):223-31.

6. Boelen C: Social accountability and the future of medical education. Wilson Centre for Research in Education, University of Toronto, Centre de pédagogie appliquée aux sciences de la santé, Université de Montréal, Health Canada; 2008 [http://www.afmc.ca/fmec/pdf/National\%20Literature\%20Reviews.pdf].

7. Boelen C. Social accountability and excellence. Educ méd. 2009;12(4):199-205.

8. Boelen C. Social accountability: The mark of excellence in health professional. education. In: Teaching to cure - Teaching to Care. Balancing the dynamics in health sciences education.: 30 June - 2 July 2011. South Africa: Faculty of Health Sciences, North-West University, Potchefstroom Campus; 2011.

9. Boelen C, Dharamsi S, Gibbs T. The social accountability of medical schools and its indicators. Educ Health. 2012;25:180-94. http://www. educationforhealth.net/text.asp?2012/25/3/180/109785.

10. Boelen C, Woollard R. Social accountability and accreditation: A new frontier for educational institutions. Med Educ. 2009;43(9):887-94

11. Bhutta Z, Chen L, Cohen J, Crisp N, Evans T, Fineberg H, Frenk J, Garcia P, Horton $\mathrm{R}$, Ke $\mathrm{Y}$, et al. Education of health professionals for the 21st century: A global independent commission. Lancet. 2010;375(9721):1137-8.

12. Carter S, Little M. Justifying knowledge, justifying method, taking action: Epistemologies, methodologies, and methods in qualitative research. Qual Health Res. 2007;17(10):1316-28.

13. Patton M. Qualitative research and evaluation methods. 3rd ed. London: Sage; 2002.

14. Bleakley A, Brice J, Bligh J. Thinking the post-colonial in medical education. Med Educ. 2008:42(3):266-70.

15. Crane J. Scrambling for Africa? Universities and global health. Lancet. 2011; 377:1388-90.

16. Wolinsky F. The professional dominance perspective, revisited. Milbank Q. 1988;66(Supplement 2):33-47.

17. Germov J. Challenges to medical dominance. In: Germov J, editor. Second opinion. South Melbourne: Oxford University Press; 2002.

18. Turner B. Medical power and social knowledge. 2nd ed. London: Sage Publications; 1995

19. Wartenberg T. The forms of power. Philadelphia: Temple University Press; 1990.

20. Hafferty F. Theories at the crossroads: A discussion of evolving views on medicine as a profession. Milbank Q. 1988;66(Supplement 2):202-25.

21. Nugus P, Greenfield D, Travaglia J, Westbrook J, Braithwaite J. How and where clinicians exercise power: Interprofessional relations in health care. Soc Sci Med. 2010;71(5):898-909.

22. Kellner D. Critical theory and the crisis of social theory. Sociol Perspect. 1990:33(1):11-33.

23. Kincheloe J, McLaren P. Rethinking critical theory and qualitative research. In: Denzin N, Lincoln Y, editors. The Sage handbook of qualitative Research. Thousand Oaks: Sage Publications Inc; 2005. p. 303-42.

24. Thomas G. How to do your case study: A guide for students and researchers. London: Sage Publications Inc.; 2011. 
25. Stake RE. The art of case study research. Thousand Oaks: Sage Publications; 1995.

26. Baxter P, Jack S. Qualitative case study methodology: Study design and implementation for novice researchers. Qual Rep. 2008;13(4):544-59.

27. Strasser R, Neusy A-J. Context counts: Training health workers in and for rural and remote areas. Bull World Health Organ. 2010;88:777-82.

28. Pálsdóttir B, Neusy AJ. Global health: Networking innovative academic institutions. Infect Dis Clin N Am. 2011;25(2):337-46.

29. Pálsdóttir B, Neusy A-J, Reed G. Building the evidence base: Networking innovative socially accountable medical educational programs. Educ Health. 2008;21(2):1-6.

30. Neusy A-J, Pálsdóttir B. A roundtable of innovative leaders in medical education. MEDICC Rev. 2008;10(4):20-4.

31. Pálsdóttir B, Neusy AJ. Transforming medical education: Lessons learned from THEnet: A paper prepared for The Commission on Education of Health Professionals for the 21st Century. 2010. Training for Health Equity Network, [http://www.healthprofessionals21.org/docs/TransformingMedEd.pdf].

32. Neusy A-J, Pálsdóttir B. Roundtable: Revisiting innovative leaders in medical education. MEDICC Rev. 2011;13(3):6-11.

33. Yin R. Enhancing the quality of case studies in health services research. Health Serv Res. 1999;34(5 Part II):1209-24.

34. Liamputtong P. Qualitative research methods. 3rd ed. South Melbourne: Oxford University Press; 2009.

35. Abma TA, Stake RE. Science of the particular: an advocacy of naturalistic case study in health research. Qual Health Res. 2014;24(8):1150-61.

36. QSR International: NVivo 10. In:: QSR International Pty Ltd; 2012. Computer Software.

37. Silver C, Lewins A. Using software in qualitative research: a step by step guide. 2nd ed. London: Sage Publications Inc; 2014.

38. Miles M, Huberman A. Qualitative data analysis: An expanded sourcebook. 2nd ed. Thousand Oaks: Sage Publications Inc; 1994.

39. Seale C. Qualitative methods: Validity and reliability. Eur J Cancer Care. 2001; 10(2):133-4

40. Murray R, Larkins S, Russell H, Ewen S, Prideaux D. Medical schools as agents of changes: Socially acountabile medical education. Med J Aust. 2012; 196(10):653.

41. Biggs J, Wells R. The social mission of Australian medical schools in a time of expansion. Aust Health Rev. 2011;35(4):424-9. http://dx.doi.org/10.1071/ AH10970.

42. World Health Organization. Policy brief on regulation of health professions education. Geneva: World Health Organization; 2013.

43. World Health Organization. Policy brief on accreditation of institutions for health professional education. Geneva: World Health Organization; 2013.

44. Howe A. Twelve tips for community-based medical education. Med Teach. 2002;24(1):9-12

45. Rourke J. Social accountability in theory and practice. Ann Fam Med. 2006; 4(s1):S45-48. discussion S58-60.

46. Health Canada. Social accountability: A vision for Canadian medical schools. Ottawa: Health Canada; 2001 [http://www.afmc.ca/pdf/pdf_sa_vision_ canadian_medical_schools_en.pdf].

47. Lindgren S, Karle H. Social accountability of medical education: Aspects on global accreditation. Med Teach. 2011;33(8):667-72.

48. Sen Gupta T, Murray R, McDonell A, Murphy B, Underhill A. Rural internships for final year students: Clinical experience, education and workforce. Rural Remote Health. 2008;827.

49. Dussault G, Franceschini M. Not enough there, too many here: Understanding geographical imbalances in the distribution of the health workforce. Hum Resour Health. 2006:4(1):12.

50. Towle A, Godolphin W. Patient involvement in health professional education. In: Dornan T, Mann K, Scherpbier A, Spencer J, editors. Medical education theory and practice. Edinburgh: Churchill Livingstone Elsevier; 2011. p. 65-77.

51. Australia. Department of health: rural clinical training and support (RCTS) 2011-2014 - operational framework: attachment a - rural clinical training and support (RCTS) program parameters. Canberra: Health Workforce Australia; 2012 [http://www.health.gov.au/internet/publications/publishing. nsf/Content/work-st-rcts-2011-14-toc work-st-rcts-2011-14-atta].

52. Hunt J, Bonham C, Jones L. Understanding the goals of service learning and community-based medical education: A systematic review. Acad Med. 2011; 86(2):246-51.

53. Holley KA. Rural minority student engagement with a healthcare pipeline program. J Res Rural Educ (Online). 2013;28(4):1-11.
54. Kelly L, Walters L, Rosenthal D. Community-based medical education: Is success a result of meaningful personal learning experiences? vol. 27. 2014.

55. Woollard R. Caring for a common future: Medical schools' social accountability. Med Educ. 2006;40(4):301-13.

56. Evans C. The dean as spiritual leader. Acad Med. 1998;73(6):645-8.

57. Jippes M, Driessen EW, Majoor GD, Gijselaers WH, Muijtjens AMM, van der Vleuten CPM. Impact of national context and culture on curriculum change: A case study. Med Teach. 2013;35(8):661-70.

58. Kayyal M, Gibbs T. Managing curriculum transformation within strict University governance structures: An example from Damascus University Medical School. Med Teach. 2012;34(8):607-13.

59. Cohen J, Dannefer E, Seidel H, Weisman C, Wexler P, Brown T, Brieger G, Margolis S, Ross L, Kunitz S. Medical education change: A detailed study of six medical schools. Med Educ. 1994;28(5):350-60.

60. Guilbert J. Why is it taking so long for healthcare professional education to become relevant and effective? What can be done? vol. 27. 2014.

61. Boelen C. Medical education reform: The need for global action. Acad Med. 1992;67(11):745-9.

62. Ghoshal S, BonTempo J. Modern communities of practice: Recommendations for building, maintaining and measuring impact. Health Communication Capacity Collaborative, USAID, John Hopkins University; 2014

63. Wenger E, McDermott R, Snyder W. Cultivating communities of practice: A guide to managing knowledge. Boston: Harvard Business School; 2002.

64. Galukande M, Nakasujja N, Sewankambo N. Social accountability: A survey of perceptions and evidence of its expression at a Sub Saharan African university. BMC Med Educ. 2012;12(1):96.

65. Reddy AT, Lazreg SA, Phillips RL, Bazemore AW, Lucan SC. Toward defining and measuring social accountability in graduate medical education: A stakeholder study. J Grad Med Educ. 2013;5(3):439-45.

66. Puschel K, Rojas P, Erazo A, Thompson B, Lopez J, Barros J. Social accountability of medical schools and academic primary care training in Latin America: Principles but not practice. Fam Pract. 2014. doi:10.1093/ fampra/cmu010

67. Rudolf M, Reis S, Gibbs T, Murdoch Eaton D, Stone D, Grady M, Berlin A, Blair M, Essa-Hadad J, Spitzer-Shohat S, et al. How can medical schools contribute to bringing about health equity? Israel J Health Policy Res. 2014;3(1):17.

68. Jamieson J, Snadden D, Dobson S, Frost H, Voyer S. Health disparities, social accountability and postgraduate medical education: A paper commissioned as part of the environmental scan for the Future of Medical Education in Canada Postgraduate Project. 2011. Members of the FMEC PG consortium, [http://www.afmc.ca/pdf/fmec/01_Jamieson_Health\%20Disparity.pdf].

69. Ritz S, Beatty K, Ellaway R. Accounting for social accountability: Developing critiques of social accountability within medical education, vol. 27. 2014.

70. McCrea ML, Murdoch-Eaton D. How do undergraduate medical students perceive social accountability? Med Teach. 2014;36(10):867-75.

\section{Submit your next manuscript to BioMed Central and we will help you at every step:}

- We accept pre-submission inquiries

- Our selector tool helps you to find the most relevant journal

- We provide round the clock customer support

- Convenient online submission

- Thorough peer review

- Inclusion in PubMed and all major indexing services

- Maximum visibility for your research

Submit your manuscript at www.biomedcentral.com/submit 